\title{
Pudicinae (Nematoda) coparasitic in Proechimys roberti (Rodentia: Echimyidae) from the Brazilian Amazonia: description of a new species of Pudica, redescription of Pudica evandroi (Travassos) and updated key to the species of the genus
}

\author{
PAULA C. SERRANO ${ }^{1}$, MARIE-CLAUDE DURETTE-DESSET ${ }^{2}$ and MARÍA C. DIGIANI ${ }^{1, *}$ \\ ${ }^{1}$ División Zoología Invertebrados, Facultad de Ciencias Naturales y Museo, Universidad \\ Nacional de La Plata, Paseo del Bosque, s/n, 1900 La Plata, Argentina \\ ${ }^{2}$ Institut Systématique, Évolution, Biodiversité/ISYEB, UMR7205 CNRS, EPHE, UPMC, Muséum National \\ d'Histoire Naturelle/MNHN, Sorbonne Universités, 61, rue Buffon, 75231 Paris cedex 05, France
}

Manuscript received on July 18, 2018; accepted for publication on December 27, 2018

\begin{abstract}
How to cite: SERRANO PC, DURETTE-DESSET MC AND DIGIANI MC. 2019. Pudicinae (Nematoda) coparasitic in Proechimys roberti (Rodentia: Echimyidae) from the Brazilian Amazonia: description of a new species of Pudica, redescription of Pudica evandroi (Travassos) and updated key to the species of the genus. An Acad Bras Cienc 91: e20180714. DOI. 10.1590/0001-3765201920180714.
\end{abstract}

\begin{abstract}
The re-examination of nematodes collected decades ago from a spiny rat, Proechimys roberti (Echimyidae) from Pará State, revealed the presence of Acanthostrongylus acanthostrongylus Travassos, 1937, and two coparasitic species of Pudica (Heligmonellidae: Pudicinae), one of them new to science. Pudica minima n. sp. mostly resembles Pudica tenua Durette-Desset, 1970, described from Proechimys semispinosus in Colombia. Nevertheless, it differs from $P$. tenua by having a synlophe with 12 ridges with poorly developed careen, bursal pattern of type 2-2-1 on the right lobe, bursal rays 2 and 3 similar in length, and spicules longer with spoon-shaped tips. Pudica evandroi (Travassos, 1937) was already described from Pr. roberti but its synlophe remained undescribed and the original description lacked some details. A detailed study of the synlophe is provided and the range of morphometric data for males and females is enlarged. The study of the synlophe allowed ratifying the placement of this species within Pudica, as early suggested by previous authors. The species list and identification key to species of Pudica are updated with the inclusion of three species. The status of Heligmosomum alpha Travassos, 1918, which was transferred to Pudica in 1990, is emended and the species is considered a Nippostrongylinae incertae sedis.
\end{abstract}

Key words: Heligmonellidae, Heligmosomum alpha, Pará State, Pudica minima n. sp., spiny rats, synlophe.

\section{INTRODUCTION}

The genus Proechimys Allen, 1899 is the most speciose and geographically most widely distributed of the Echimyidae rodents. Known commonly as "spiny rats", all species are essentially

Correspondence to: María Celina Digiani

E-mail: mdigiani@fcnym.unlp.edu.ar

ORCid: https://orcid.org/0000-0002-1626-9309

*CONICET limited to lowland rainforest habitats in Central America and Amazonian South America, where they are important components of the terrestrial forest community, serving as seed predators and dispersal agents (Patton and Leite 2015). Species of Proechimys are of public health interest as they act as reservoirs of parasitic zoonoses such as leishmaniasis and trypanosomiasis (Cordeiro et al. 2015a, Patton and Leite 2015). The genus 
comprises at present 22 species distributed in 10 species groups (Patton and Leite 2015). Among them, Proechimys roberti Thomas, 1901 occurs throughout the rainforest of Amazonian Brazil south of the Amazonas River and extends south to the Cerrado biome in East-central Brazil (Weksler et al. 2001). There have been relatively few studies examining the helminth fauna of this species (Cordeiro et al. 2015a). To date, it has been cited as host of seven species of nematodes: four out of them are Heligmonellidae: Acanthostrongylus acanthostrongylus Travassos, 1937, Pudica evandroi (Travassos, 1937), Heligmostrongylus squamastrongylus (Travassos, 1937), and Squamasnema amazonica Cordeiro, Melo, Furtado, Giese, Maldonado Jr. and dos Santos, 2015. The other species are Molinema dessetae (Bain, 1973) (Onchocercidae), Spirura carajaensis Cordeiro, Melo, Maldonado and Santos, 2015 (Spiruridae) and one species of Gongylonema Molin, 1857 (Travassos 1937, Bain 1973, Vicente et al. 1997, Cordeiro et al. 2015a, b, Durette-Desset et al. 2017). Up to now, for all these species except for Gongylonema sp., Pr. roberti is the type and unique host. The old parasitological literature (Travassos 1937) refer the host of $A$. acanthostrongylus, $P$. evandroi and H. squamastrongylus to as Proechimys oris Thomas, 1904. However, more recent studies indicate that Pr. oris should be considered a junior synonym of Pr. roberti (Weksler et al. 2001, Patton and Leite 2015).

In 1971, several nematodes collected from one Pr. roberti from Pará State were deposited at the Muséum national d'Histoire naturelle (MNHN) (Paris, France). These nematodes are studied herein. Among this material, three coparasitic taxa were identified: A. acanthostrongylus, $P$. evandroi, and other specimens belonging to a new species of Pudica Travassos and Darriba,1929 (Heligmonellidae: Pudicinae). In this paper, the new species is described and illustrated, a redescription of $P$. evandroi (whose synlophe remained unknown) is provided, and an updated key to the species of Pudica is included. The ZooBank Life Science Identifier (LSID) of this publication is: urn:1sid:zoobank.org:pub:DBEDBE0D-23964E4E-BD41-8C46C75F333E.

\section{MATERIALS AND METHODS}

The material was deposited at the Muséum national d'Histoire naturelle (MNHN) (Paris, France) under the number $136 \mathrm{RL}$. It consisted of nematodes collected from a Pr. roberti from Itaituba (Pará State, Brazil) in 1971, in the frame of a project involving the survey for sylvatic reservoirs of $T$. cruzi-like trypanosomes under the auspices of the Wellcome Trust (London, UK) and the Instituto Evandro Chagas (Belém, Brazil) (see Lainson et al. 1979).

The nematodes were recovered in the field and identified preliminary by one of us (MCDD) as $P$. evandroi at the time of collection. Their study started at the MNHN shortly after recovery but it was arrested for several years, until it was restarted at the Division Zoología Invertebrados of the Museo de La Plata (La Plata, Argentina).

Nematodes were studied in temporary mounts in Amman's lactophenol under a Leica DM 2500 microscope provided with a drawing attachment. The synlophe was studied following Durette-Desset (1985) and the nomenclature referring to the axis of orientation of the ridges follows Durette-Desset and Digiani (2005). Ridges are numbered with respect to the oblique axis of orientation: from left to right, 1 to $\mathrm{n}$ for right-dorsal ridges and 1' to $\mathrm{n}$ ' for leftventral ridges. The nomenclature used for the study of the bursa (pattern of lateral lobes and symmetry) follows Durette-Desset and Digiani (2012). Figures $8,11 \mathrm{~b}$ and 26 are original drawings made in 1971, whose scale bars are missing. Measurements are provided in micrometres (except body length, in $\mathrm{mm}$.), as follows: in the new species description, holotype/allotype followed by range and mean of 
paratypes in brackets; in the redescription of $P$. evandroi, range followed by mean in parenthesis. $\mathrm{SpL} / \mathrm{BL}$ and UtL/BL mean the proportion of the spicule length to the body length and of the uterus length to the body length, respectively. The type material of the new species described was deposited at the Helminthological Collection of the Instituto Oswaldo Cruz (CHIOC), Rio de Janeiro.

\section{RESULTS}

\section{Pudica minima n. sp.}

Figures 1-12

ZooBank Life Science Identifier (LSID) urn:1sid:zoobank.org:act:F2A52DC8-788D-48E9A442-741786BC49EF.

General. Very small nematodes, irregularly coiled, with coiling mainly affecting the anterior part of the body. Excretory pore situated anterior to oesophago-intestinal junction in both sexes (43$82 \%$ of oesophagus length in males and $56-89 \%$ in females). Deirids situated asymmetrically with respect to the apex, with left deirid at level of the excretory pore and right deirid some $20 \mu \mathrm{m}$ more anteriorly (Figure 1).

Head. Cephalic vesicle present. In apical view, rounded buccal opening, surrounded by thick ring. Four externo-labial (dorsal and ventral) and four submedian cephalic papillae visible. Lateral externolabial probably fused with amphids (Figure 2).

Synlophe (studied in 2 males and 2 females). In both sexes cuticle bearing longitudinal, uninterrupted ridges, most of them appearing posterior to cephalic vesicle. Twelve ridges (careen, 5 right-dorsal and 5 left-ventral) in both sexes, at oesophago-intestinal junction, at mid-body and posterior third of body. From oesophago-intestinal junction to mid-body, ridges forming careen largest but not hypertrophied (Figures 3-6). Remaining ridges medium to small. Gradient in ridge size absent. Dorsal ridges similar in size. Male: at midbody, ridges 2'and 3' larger than 4'-6' (Figure 3).
Female: at anterior third of body length, ridges 2'4' larger than 5' and 6', upper part of right-ventral quadrant free of ridges (Figure 5). From mid-body, ridges 2' and 5' diminishing in size and ridges forming careen less salient (Figure 6). At level of uterus, all ridges small and similar in size and careen not differentiated. Some struts not visible (Figure 7). Axis of orientation of ridges single, inclined at about $45^{\circ}$ to sagittal axis in both sexes.

Males [holotype and 14 (except indication) paratypes from $P r$ roberti]. Body 1.94 [1.37-2.02; $1.61] \mathrm{mm}$ long and $40[28-48 ; 37]$ wide at midbody. Cephalic vesicle 22 [20-28; 23] long and 20 [15-20; 17] wide. Nerve ring, excretory pore and left deirid situated at $82[80-130 ; 110](\mathrm{n}=8)$, 170 [115-200; 151] $(\mathrm{n}=11)$ and 170 [128-195; 165] $(n=4)$ from apex, respectively. Right deirid situated at about 20 in front of the level of left deirid. Oesophagus 240 [178-270; 225] long.

Bursa subsymmetrical (Figure 8). Prebursal papillae not observed. Right lobe with pattern of type 2-2-1. Left lobe with pattern of type 2-2-1 tending to 1-3-1. Rays 2 and 3 parallel and similar in length. Rays 4 and 5 diverging slightly at distal part of their length. Rays 6 long and straight, with similar diameter through their length. Dorsal lobe medium-sized. Dorsal ray strongly thickened, especially dorso-ventrally, divided at about distal third into two branches (Figures 9, 10). Each branch divided into two sub-branches, rays 9 (external) and rays 10 (internal). Rays 8 of similar length, not reaching level of extremity of dorsal ray, arising from the ventral surface of the dorsal ray at the angle of the dorsal ray and the lateral common trunk of rays 2 to 6 (Figure 9). Origin of rays 8 not clearly visible in dorsal view due to the thickening of dorsal ray and both lateral trunks at their base (Figure 10). Genital cone stout, shortly conical, hardly visible. Papillae on genital cone not observed. Spicules subequal, alate, 460 [370-450; 413] $(n=7)$ long, with spoon-shaped tips (Figure 11). SpL/BL 23.7\% [21.3-31.3\%; 25.8\%]. 


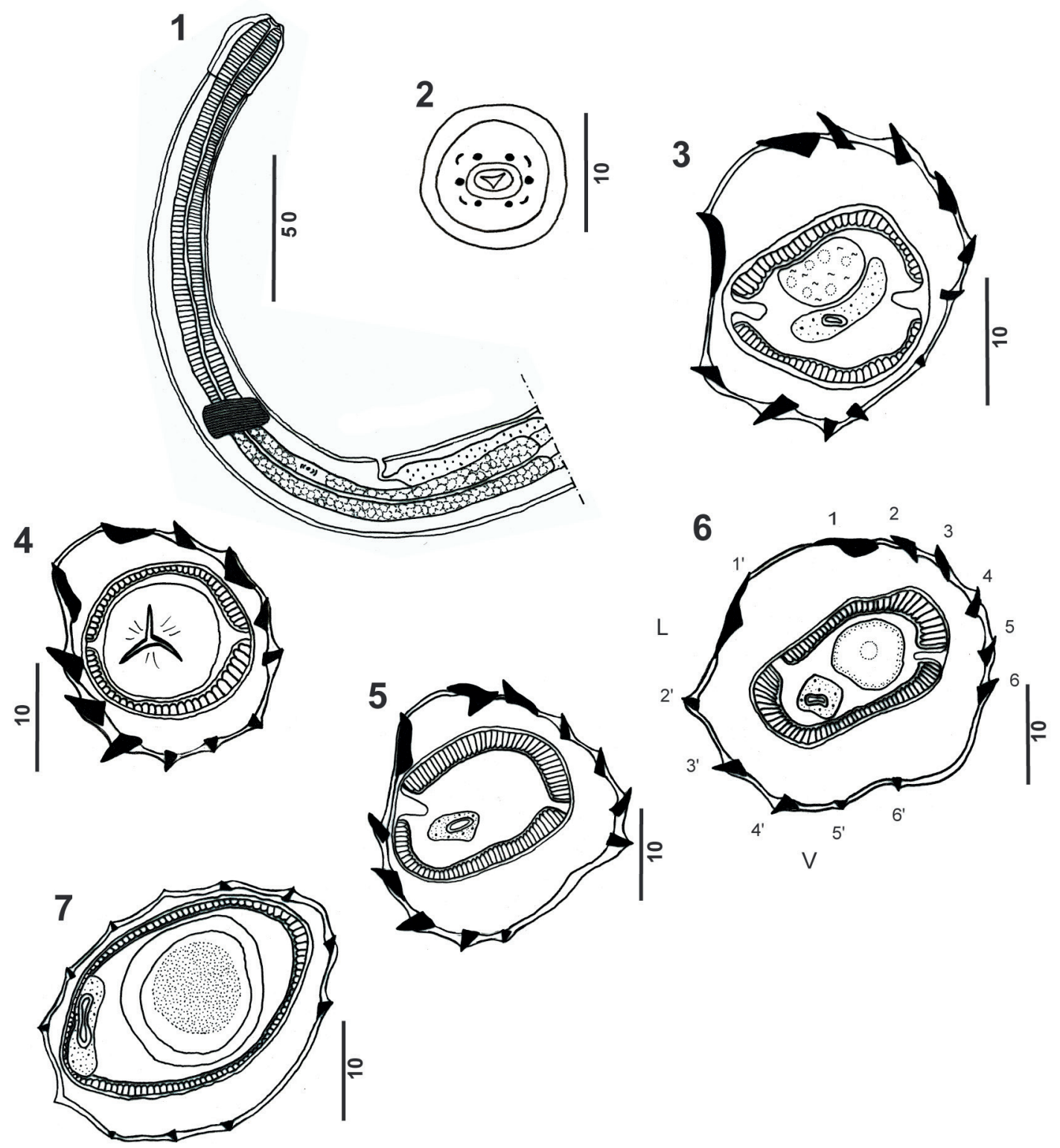

Figures 1-7 - Pudica minima n. sp. 1, 2 female. 1, anterior extremity, right lateral view. 2, head, apical view. 3-7, synlophe in transverse sections of the body. 3, male, at mid-body. 4-7, female. 4, at oesophago-intestinal junction. 5, within anterior third of body length. 6, at mid-body. 7, at level of uterus. Abbreviations: L: left, V: ventral. Scale bars in $\mu \mathrm{m}$. All sections oriented as in Fig. 6.

Females [allotype and 19 (except indication) paratypes from Pr. roberti]. Body 1.67 [1.39-2.08; $1.60] \mathrm{mm}$ long and $35[30-43 ; 37]$ wide at midbody. Cephalic vesicle 25 [15-28; 22] long and 15 [15-20; 17] wide. Nerve ring, excretory pore and left deirid situated at $80[65-120 ; 85](n=12)$, 160 [120-165; 147] $(\mathrm{n}=14)$ and 156 [118-165; 146] $(\mathrm{n}=8)$ from apex, respectively. Right deirid situated at about 20 in front of the level of left deirid. Oesophagus 238 [145-225 (187)] long. Reproductive tract monodelphic. Vulva situated at 70 [60-115; 81] from caudal extremity. Vagina vera [12-30; 19] $(\mathrm{n}=10)$ long, vestibule 60 [30-60; 42] $(\mathrm{n}=13)$ long, sphincter 20 [22-30; 25] long and 30 [25-45; 34] $(\mathrm{n}=14)$ wide, infundibulum 60 [48-70; 58] $(\mathrm{n}=4)$ long. Uterus 330 [215-380; 288] $(\mathrm{n}=11)$ 
long, containing 1-3 eggs, 55 [45-72; 61] long and $30[25-30 ; 28](\mathrm{n}=17)$ wide. UtL/BL 19.8\% [14.4-26.2\%; 18.6\%]. Posterior extremity tapering abruptly just behind vulva. Tail thin, bluntly conical, 40 [35-55; 42] long (Figure 12).

REMARKS

The presence of a cephalic vesicle and a synlophe with an axis of orientation not bilaterally symmetrical places these specimens into the superfamily Heligmosomoidea, as redefined by Durette-Desset (1983) and Durette-Desset and Chabaud (1993), which is composed of six families. Two of these, the Heligmonellidae and the Viannaiidae are well represented in caviomorph rodents. The presence of a careen and spicules with conspicuous alae, together with the absence of gubernaculum in the present specimens, allow to assign them to the Heligmonellidae: Pudicinae. Among these, and according to Durette-Desset and Justine (1991) and Durette-Desset et al. (2017), the following characters enable us to assign this species to the genus Pudica: synlophe with careen made up of two continuous ridges, three to five continuous dorsal ridges, three to five continuous ventral ridges, at least two ventral comaretes present, together with a bursa of type 2-2-1 and 9th rays slightly longer than 10 th. Within the genus, these specimens strongly resemble Pudica tenua Durette-Desset, 1970, parasitic in Proechimys semispinosus Tomes, 1860 from Colombia, by the tiny body size, the dissymmetrical position of the deirids (only recorded in these two species), the bursal pattern and general arrangement of the bursal rays, and the similar number of ridges of the synlophe (11-12). However, these specimens are differentiated from $P$. tenua by a bursal pattern of type 2-2-1 on right lobe (vs. 2-2-1 t 1-3-1), rays 2 and 3 similar in length (vs. rays 2 shorter), rays 8 not reaching level of extremity of dorsal ray, branches of dorsal ray bifid (vs. trifid, with phasmids visible), origin of rays 8 from the angle of dorsal ray and lateral trunks (vs. from proximal third of dorsal ray), longer spicules (370-460 $\mu \mathrm{m}$ vs. $182 \mu \mathrm{m}$ ) with spoon-shaped tips (vs. sharp tips) and greater SpL/BL (21-31\% vs. 14\%). Differences concerning the synlophe at mid-body are: careen less developed, 12 ridges (vs. 11 in the figure of $P$. tenua), and ridges 3' and 4' well developed (vs. 2', 3 ' and 4'). These differences allow us to consider these specimens as a new species, for which the name Pudica minima n. sp. is proposed.

\section{TAXONOMIC SUMMARY}

Type host. Proechimys roberti (Echimyidae).

Site. Small intestine.

Type locality. Itaituba, Pará State, Brazil.

Type material. Holotype male CHIOC 38703a, allotype female CHIOC 38703b, 6 males, 7 females paratypes CHIOC 38703c, 10 males and 20 females paratypes MNHN 136 RL.

Etymology. The specific name refers to the extremely small size of the specimens.

Intensity of infection. The only examined host harboured 50 worms (18 males, 32 females).

Coparasitism. Coparasitic with $P$. evandroi (10 males, 8 females) and A. acanthostrongylus (1 male, 1 female).

\section{Pudica evandroi (Travassos, 1937)}

Evandroia evandroi Travassos, 1937: 352.

Pudica evandroi - Durette-Desset, 1983: 60.

Figures 13-30

\section{REDESCRIPTION}

Synlophe (studied in 1 male and 2 females). In both sexes cuticle bearing longitudinal, uninterrupted ridges appearing posterior to cephalic vesicle. Number of ridges at oesophago-intestinal junction: 13 in both sexes, including careen made up of two medium-sized ridges. Of 11 remaining ridges, five right-dorsal and three left-ventral well oriented and 

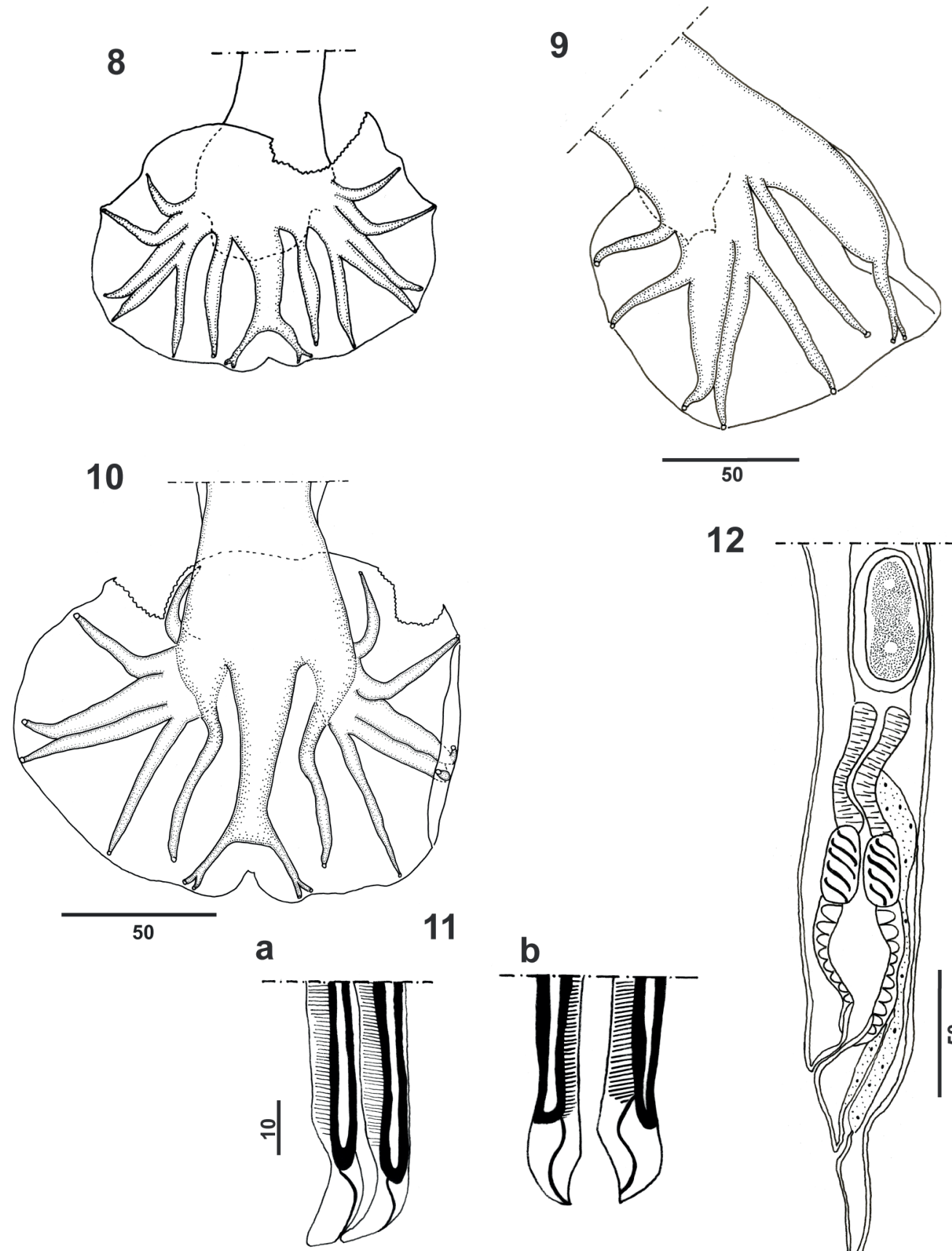

50

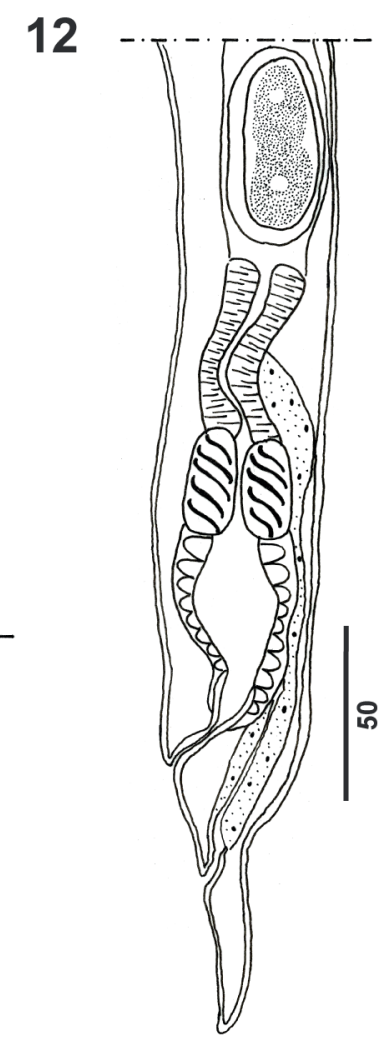

Figures 8-12 - Pudica minima n. sp. 8-11, male. 8-10, bursa. 8, ventral view 9, left lateral view. 10, dorsal view. 11, tips of spicules in different observed positions, (a) parallel, (b) convergent. 12, female, posterior extremity, left lateral view. Scale bars in $\mu \mathrm{m}$.

with cuticular struts; remaining three, on rightventral quadrant, smaller and perpendicular to body surface, without cuticular struts at this level (Figures 13, 14). These three smaller ridges acquire cuticular struts but remain poorly developed and without orientation, disappearing at mid-body in females and at $60 \%$ of total length in males, leaving right-ventral quadrant free of ridges (Figures 15 20). At mid-body: 13 ridges in male, 10 in female (Figures 18, 19). Size of ridges: at the anterior half 


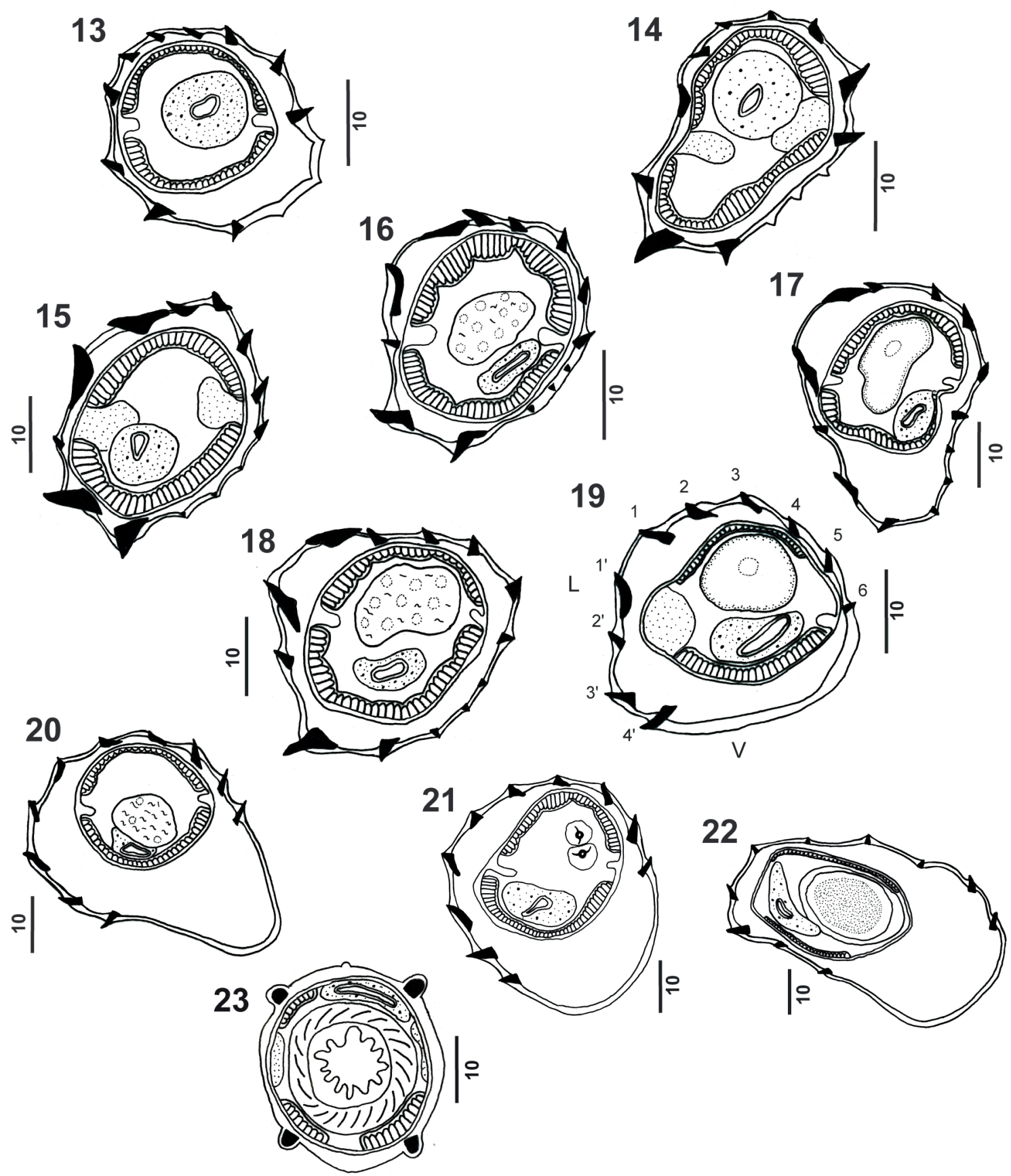

Figures 13-23 - Pudica evandroi. 13-23, synlophe in transverse sections of the body. 13, 14, at oesophago-intestinal junction. 13, male. 14, female. 15-17, at different levels anterior to mid-body. 15, female at $26 \%$ of body length. 16 , male at $39 \%$ of body length. $\mathbf{1 7}$, female at $45 \%$ of body length. 18-19, at mid-body (50\%). 18, male. 19, female. 20-23, posterior to mid-body. $\mathbf{2 0}, \mathbf{2 1}$, male. $\mathbf{2 0}$, at $60 \%$ of body length. $\mathbf{2 1}$, at $80-85 \%$ of body length. $\mathbf{2 2}, \mathbf{2 3}$ female. $\mathbf{2 2}$, at $75 \%$ of body length. 23, at sphincter level, showing ridges forming prevulvar alae. Abbreviations: L: left, V: ventral. Scale bars in $\mu \mathrm{m}$. All sections oriented as in Fig. 19.

of body, medium to small with those forming careen largest. Gradient in ridge size absent. Ventral ridges: 3' and 4' larger than 2'. Dorsal ridges: similar in size. From mid-body in females, and from $60 \%$ of body length in males, ridges of careen and ventral 3 ' and 4' less developed (Figures 19, 20). At level 
of spicules in males (80-85\% of BL) and at level of uterus in females (ca. 75\% of BL): 10 in both sexes, all ridges small and similar in size; right-ventral quadrant still free of ridges (Figures 21, 22). From ovejector level, ridges of synlophe widened to form prevulvar alae: two latero-ventral and two laterodorsal. In one of the two observed females, one medio-dorsal ala also present (Figure 23). Axis of orientation of ridges single, inclined at about $55^{\circ}$ to sagittal axis in both sexes. Disappearance of ridges within the $200 \mu \mathrm{m}$ proximal to bursa in males, just proximal to vulva in females.

General. Small nematodes, irregularly coiled, with coiling mostly affecting the anterior half of the body. Excretory pore situated anterior to oesophago-intestinal junction in both sexes (55$86 \%$ of oesophagus length in males and $77-80 \%$ in females). Deirids situated symmetrically with respect to the apex (Figure 24).

Head. Cephalic vesicle present. In apical view, rounded buccal opening surrounded by very thick ring. Papillae not observed (Figure 25).

Males [eight specimens (except indication) from Pr. roberti]. Body 1.76-2.47 (2.07) mm long and 40-60 (49) wide at mid-body. Cephalic vesicle 20-28 (25) long and 17-25 (21) wide. Nerve ring, excretory pore and deirids situated at 95-140 (122) $(n=5), 105-195(168)$ and 97-198 (154) $(n=4)$ from apex, respectively. Oesophagus 180-245 (216) long.

Bursa subsymmetrical. Prebursal papillae observed (Figure 26). Pattern of type 1-3-1 on right lobe and 2-2-1 tending to 1-3-1 on left lobe. Thick common trunk of rays 2 to 6 . Rays 2 and 3 parallel and thin, rays 3 slightly longer. Rays 4 and 5 thick, diverging at distal part of their length. Rays 6 thin, arising from common trunk at same level than ray 2 (right lobe) or between rays 2 and 3 (left lobe). Dorsal lobe medium-sized. Dorsal ray strongly thickened, cylindrical, with rounded bottom. Two thin branches arising asymmetrically from it, right branch arising more ventrally. Each branch divided at distal end into two sub-branches: rays 9 (external), slightly longer and rays 10 (internal). Rays 8 thin, parallel and close to rays 6 , arising symmetrically from the angle between the dorsal ray and the common trunk of rays 2 to 6 (Figure 27). Genital cone inconspicuous, genital papillae not observed. Spicules subequal, alate, 350-435 (383) long, each ending in blunt tip with spineshaped distal process, SpL/BL 16.3-22.2\% (18.5\%) (Figure 28).

Females [six specimens (except indication) from Pr. roberti]. Body 1.68-2.18 (1.97) mm long and 40-55 (46) wide at mid-body. Cephalic vesicle 20-30 (24) long and 13-25 (21) wide. Nerve ring, excretory pore and deirids situated at 100-120 (110) $(\mathrm{n}=3), 143-165$ (153) $(\mathrm{n}=3)$ and 140-152 (146) $(n=2)$ from apex, respectively. Oesophagus 160270 (203) long. Reproductive tract monodelphic. Infundibulum 45-90 (68) $(\mathrm{n}=4)$ long, sphincter 1828 (23) long and 25-32 (27) wide, vestibule 38-65 (52) long, vagina vera $8(n=2)$ long. Vulva situated at 60-78 (69) from caudal extremity (Figure 29). Uterus 190-415 (296) long $(n=4)$, containing 3-4 eggs, 45-65 long and 20-30 wide. UtL/BL 11.319.8\% (14.6\%). Prevulvar alae present (Figure 30 $\mathrm{a}, \mathrm{b})$. Posterior end gradually tapering. Tail bluntly conical, 28-60 (38) long.

\section{TAXONOMIC SUMMARY}

Host. Proechimys roberti (Echimyidae).

Locality. Itaituba, Pará State, Brazil.

Site. Small intestine.

Material examined. Ten males, 8 females, MNHN 136 RL.

Intensity of infection. The only examined host harboured 18 worms (10 males, 8 females).

Coparasitism. Coparasitic with P. minima n. sp. (18 males, 32 females) and A. acanthostrongylus (1 male, 1 female). 


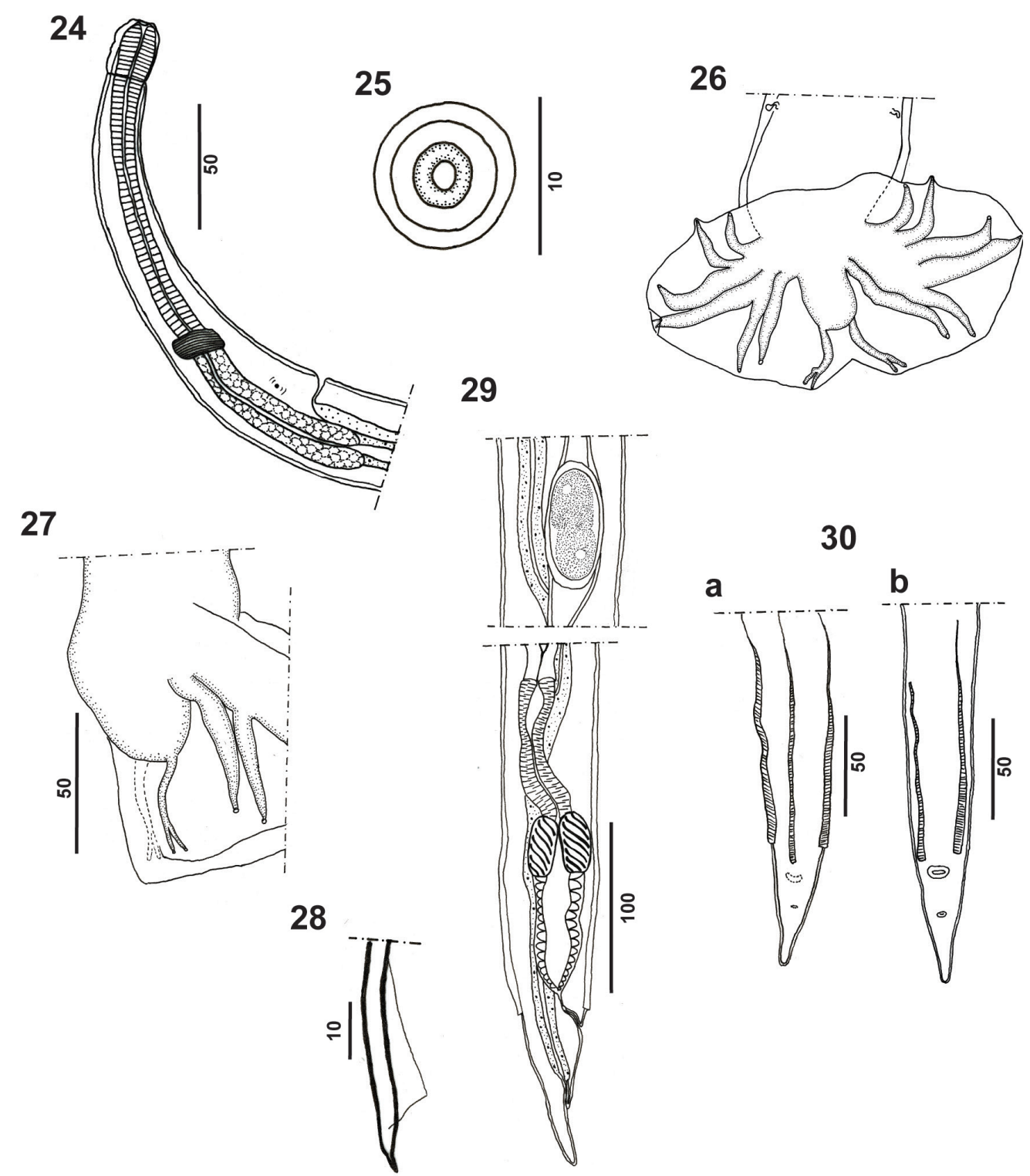

Figures 24-30 - Pudica evandroi. 24, 25, female. 24, anterior extremity, right lateral view. 25, head, apical view. 26-28, male. 26, 27, bursa. 26, ventral view. 27, dorsal ray, right lateral view, showing origin of right ray 8. 28, tip of a single spicule. 29, 30, female. 29, posterior extremity showing ovejector and first egg, right lateral view. 30, posterior end showing prevulvar alae, (a) dorsal view, (b) ventral view. Scale bars in $\mu \mathrm{m}$.

\section{REMARKS}

The specimens described herein have morphological and morphometric characters that match those of $P$. evandroi. Evandroia evandroi Travassos, 1937 was the type and sole species of Evandroia Travassos, 1937 but Durette-Desset (1983) synonymized Evandroia with Pudica, arguing that the synlophes of the type species of both genera were identical. However, the synlophe of $P$. evandro $i$ has never been formally described (Durette-Desset et al. 2017). In this work, new characters are provided which complete the original description, including the synlophe and a more detailed description of the bursa, noting the 
peculiar form and thickness of the dorsal ray and the asymmetrical arising of its branches. On the other hand, the range of morphometric data is enlarged, including measurements of uterus, infundibulum and vestibule in females.

The classification of the Pudicinae into genera is based mainly on characters of the synlophe (Durette-Desset and Justine 1991, Durette-Desset et al. 2017). Even though the synlophe of the specimens studied herein is not exactly identical to that of the type species of Pudica, as argued by Durette-Desset (1983), the different characters observed in this structure correspond largely better to those observed in species of Pudica than to those present in any other genus of Pudicinae. These characters include a careen made up of two ridges similar in size, and the remaining ridges continuous. Such characters, together with a bursa mainly of type 2-2-1 and 9th rays slightly longer than 10th, allow us to ratify the placement of this species within the genus Pudica, as early suggested by Durette-Desset (1983) and assumed by DuretteDesset and Justine (1991) and Durette-Desset et al. (2017).

\section{DISCUSSION}

With the description of Pudica minima n. sp. the number of species of Pudicinae described from $P r$. roberti throughout its distribution increases to five. Proechimys roberti is the type and unique host for all these parasite species. Pudica minima n. sp. and $P$. evandroi were coparasitic in the same individual host. This phenomenon of coparasitism of related species is frequent among heligmonellids of rodents, and particularly in spiny rats and agoutis (Dasyproctidae), where a unique host may harbor two, three and up to five species of Pudicinae (see Durette-Desset et al. 2017, Digiani et al. 2017). Although we can strongly suspect coparasitism among the species described by Travassos (1937) from $P r$ roberti (=Pr. oris), all from the same locality and time, this phenomenon was not documented. In fact, in most taxonomic works, the coparasitism is overlooked or simply not recorded (Durette-Desset et al. 2017).

Durette-Desset et al. (2017) accounted for 13 species of Pudica, for which they also provided an identification key. Shortly after the publication of such revision, two new species were added to the genus: Pudica cattani Digiani, LandaetaAqueveque, Serrano and Notarnicola, 2017 and Pudica degusi (Babero and Cattan, 1975), both parasitic in Chilean caviomorphs (Octodontidae and Abrocomidae) (Digiani et al. 2017).

The findings of Digiani et al. (2017) together with the present description of Pudica minima n. sp., increase in three the number of known species of Pudica in comparison to those listed in Durette-Desset et al. (2017). However, just after the publication of such list, the writers realized that Pudica alpha (Travassos, 1918) should be excluded from Pudica, for the reasons explained below. Heligmosomum alpha Travassos, 1918 was described from a wild mouse "camondongo selvagem" (sic) from Angra dos Reis, State of Rio de Janeiro. The original description of $H$. alpha did not include illustrations but the species was redescribed and illustrated by Travassos (1921). The host was not identified at specific level but the author specified that it was a Muridae. The combination Longistriata alpha was then proposed by Travassos and Darriba (1929). Two years later, Henry (1931) reported the finding of L. alpha in France from a nutria or coypu, Myocastor coypus (Molina, 1782) introduced from South America. The record of Henry (1931) was a misidentification, as demonstrated by Travassos (1937), who stated that the parasite found by Henry (1931) corresponded in fact to Longistriata maldonadoi Artigas and Pacheco, 1933 (now Pudica maldonadoi), described from the same host in Brazil. Travassos (1937) clarified this matter establishing L. alpha 
sensu Henry (1931) nec Travassos (1918) as a synonym of $L$. maldonadoi.

Several years later, Durette-Desset (1990), probably based on the report of Henry (1931), assumed erroneously that L. alpha was a parasite of the coypu, and transferred L. alpha to Pudica, creating the new combination Pudica alpha. The two reasons argued for this transference were, on one hand, the similarity of the bursa to that of $P$. maldonadoi, and on the other hand, the (erroneous) assumption that the host was a caviomorph. This mistake is partially overcome in Durette-Desset et al. (2017), where P. alpha sensu Travassos appears correctly having a Muridae as type host, and $P$. alpha sensu Henry is treated as a synonym of P. maldonadoi. However, there were no longer reasons to keep the species of Travassos in Pudica, nor even in the Pudicinae. First, due to the fact that the synlophe remains unknown, second, because the host is not a caviomorph but a Muridae, and, finally, the fact that the specimens possess a gubernaculum, a typical character of the Nippostrongylinae, whereas the Pudicinae are characterized by the absence of this structure (Durette-Desset et al. 2017). We consider that these arguments are enough to dismiss the combination Pudica alpha and to declare Heligmosomum alpha as a Nippostrongylinae incertae sedis.

The number of species of Pudica is then modified to 15 , and the key to the species of the genus can be rewritten as follows:

\section{Identification key to the species of Pudica}

(In bold, species incorporated after the revision by Durette-Desset et al. 2017)

1 - Dorsal ray very long .2

1 '- Dorsal ray not very long

2- Extremities of rays 5 close to those of rays 6. Right spicule tip lodged in left spicule. Parasite of Proechimys longicaudatus from Bolivia. .P. ginsburgi
2'- Extremities of rays 5 distant from those of rays 6 . Tips of spicules free

3- Dorsal ray dividing at proximal quarter of length. Extremities of rays 6 and 8 close. Genital cone not hirsute. Parasite of Thrichomys apereoides laurenteus from Brazil P. cercomysi

3'- Dorsal ray dividing within median third of length. Extremities of rays 6 and 8 distant. Genital cone hirsute. Parasite of Dasyprocta spp. from Neotropical region. P. pudica

4- Rays 4 and 5 not strongly divergent at extremities (rays 4 curved forwards, rays 5 straig ht).......

4'- Rays 4 and 5 strongly divergent at extremities (rays 4 curved forwards, rays 5 backwards) .12

5- Rays 6 and 8 close..................................... 6

5'- Rays 6 and 8 distant................................. 8

6- Dorsal ray strongly thickened, with branches arising separately at its mid-length. Parasite of Proechimys roberti from Brazil. P. evandroi

6'- Dorsal ray not strongly thickened, divided at different levels of its length. .7

7- Rays 2 shorter than rays 3. Dorsal ray bifurcated nearly at base, rays 9 and 10 long. Parasite of Octodon degus from Chile......P. degusi

7'- Rays 2 and 3 of similar length. Dorsal ray bifurcated within middle third, rays 9 and 10 short. Parasite of $O$. degus and Abrocoma bennettii from Chile.

P. cattani

8- Dorsal ray divided within distal half ........9

8 '- Dorsal ray divided within proximal half .... .11

9- Rays 8 short, arising at mid-length of dorsal ray. In female, posterior extremity curved dorsally at right angle, presence of postvulvar cuticular expansion. Parasite of Dasyprocta azarae from Para guay. P. gonosoma

9'- Rays 8 arising proximally. In female, posterior extremity not curved, postvulvar cuticular expansion absent 10 
10- Rays 2 and 3 similar in length. Spicules with tips spoon-shaped. SpL/BL 21$31 \%$. Parasite of Proechimys roberti from Brazil.......................Pudica minima n.sp.

10'- Rays 2 shorter than rays 3. Spicules with sharp tips. SpL/BL 14\%. Parasite of Proechimys semispinosus from Colombia. P. tenua

11- Large common trunk of rays 8 and dorsal ray. Tip of spicule straight. Parasite of Ctenomys talarum from Argentina. P. ctenomydis

11 '- Very short common trunk of rays 8 and dorsal ray. Tip of spicule hook-shaped. Parasite of Microcavia niata from Bolivia. P. pujoli

12- Rays 8 spindly, markedly narrower than rays $4-6$ .13

12'- Rays 8 not spindly, comparable in thickness to rays 4-6. 14

13- Rays 9 and 10 merged. Spicules ending in single spatulate tip. Parasite of Euryzygomatomys spinosus from Brazil.......................P. gamma

13'- Rays 9 and 10 distinct. Spicules ending in single rouded tip. Parasite of Kannabateomys amblyonyx from Brazil......... nematodiriformis

14- Rays 6 as long as rays 5. Parasite of Sphiggurus villosus from Brazil..........P. castrosilvai

14'- Rays 6 shorter than rays 5. Parasite of Myocastor coypus from Brazil and Europe. P. maldonadoi

\section{ACKNOWLEDGMENTS}

The authors wish to thank Dr. Coralie Martin and M. Jimmy Cassone (Muséum national d'Histoire naturelle, Paris, France) for the loan of the specimens deposited in the Helminthological Collection of the MNHN.

\section{AUTHOR CONTRIBUTIONS}

PCS and MCD conceived and wrote the manuscript; PCS studied the nematodes and made the majority of the illustrations; MCDD collected the material and made some original illustrations; all authors critically revised the manuscript and approved the final version.

\section{REFERENCES}

BAIN O. 1973. Une nouvelle filaire de rongeur sud-américain, Dipetalonema dessetae n. sp. (Nematoda, Filarioidea). Bull Mus Natl Hist Nat 3: 309-316.

CORDEIRO H, MELO FTV, FURTADO AP, GIESE EG, MALDONADO JR A AND DOS SANTOS JN. 2015b. Squamasnema amazonica $\mathrm{n}$. gen. n. sp. (Heligmonellinae): A new parasite of Proechimys roberti (Rodentia: Echimyidae) in the Brazilian Amazon. Acta Trop 148: 4650.

CORDEIRO H, MELO FTV, MALDONADO JR A AND DOS SANTOS JN. 2015a. Spirura carajaensis n. sp. (Nematoda: Spiruridae), parasite of Proechimys roberti Thomas 1901 (Rodentia: Echimyidae) from Brazilian Amazon. Helminthologia 52: 28-33.

DIGIANI MC, LANDAETA-AQUEVEQUE C, SERRANO PC AND NOTARNICOLA J. 2017. Pudicinae (Nematoda: Heligmonellidae) parasitic in endemic Chilean rodents (Caviomorpha: Octodontidae and Abrocomidae): description of a new species and emended description of Pudica degusi (Babero and Cattan) n. comb. J Parasitol 103: 736-746.

DURETTE-DESSET MC. 1983. Keys to genera of the superfamiy Trichostrongyloidea. In: Anderson RC and Chabaud AG (Eds), CIH. Keys to the nematode parasites of vertebrates, Farnham Royal: Commonwealth Agricultural Bureaux, Bucks, England, p. 1-68.

DURETTE-DESSET MC. 1985. Trichostrongyloid nematodes and their vertebrate hosts: reconstruction of the phylogeny of a parasitic group. Adv Parasitol 24: 239-306.

DURETTE-DESSET MC. 1990. Pudica pujoli n. sp. (Nematoda, Trichostrongyloidea), parasite d'un Rongeur Caviidae de Bolivie. Ann Parasitol Hum Comp 65: 141144.

DURETTE-DESSET MC AND CHABAUD AG. 1993. Nomenclature des Strongylida au-dessus du groupe famille. Ann Parasitol Hum Comp 68: 111-112.

DURETTE-DESSET MC AND DIGIANI MC. 2005. The axis of orientation of the synlophe in the Heligmosomoidea (Nematoda, Trichostrongylina): a new approach. Parasite 12: 195-202.

DURETTE-DESSET MC AND DIGIANI MC. 2012. The caudal bursa in the Heligmonellidae (Nematoda: Trichostrongylina). Characterization and hypothesis on its evolution. Parasite 19: 3-18.

DURETTE-DESSET MC, DIGIANI MC, KILANI M AND GEFFARD-KURIYAMA D. 2017. Critical revision of the Heligmonellidae (Nematoda: Trichostrongylina: Heligmosomoidea). Mémoires du Muséum national 
d'Histoire naturelle, n. 211. Paris: Muséum national d'Histoire naturelle, $290 \mathrm{p}$.

DURETTE-DESSET MC AND JUSTINE JL. 1991. A cladistic analysis of the genera in the subfamily Pudicinae (Nematoda, Trichostrongyloidea, Heligmonellidae). Int J Parasitol 21: 579-587.

HENRY A. 1931. Les parasites et les maladies parasitaires du ragondin. Bull Soc Nat Acclimat France 78: 421-447.

PATTON JL AND LEITE RN. 2015. Genus Proechimys J.A. Allen, 1899. In: Patton JL et al. (Eds), Mammals of South America, Volume 2 Rodents, Chicago and London: University of Chicago Press, Illinois, USA, p. 950-989.

TRAVASSOS L. 1918. Trichostrongylidae brazileiros. Rev Soc Bras Sci 3: 191-205.

TRAVASSOS L. 1921. Contribuições para o conhecimento da fauna helmintolojica brasileira. XIII: ensaio monográfico da família Trichostrongylidae LEIPER, 1909. Mem Inst Oswaldo Cruz 13: 5-135.

TRAVASSOS L. 1937. Revisão da família Trichostrongylidae Leiper, 1912. Monographias Inst Oswaldo Cruz 1: 1-512.

TRAVASSOS L AND DARRIBA AR. 1929. Notas sobre Heligmosominae. Medicina de los Países Cálidos 2: 563569.

VICENTE JJ, RODRIGUES HO, GOMES DC AND PINTO RM. 1997. Nematóides do Brasil. Parte V; nematóides de mamíferos. Rev Bras Zool 14: 1-452.

WEKSLER M, BONVICINO CR, OTAZU IB AND SILVA JS. 2001. Status of Proechimys roberti and P. oris (Rodentia: Echimyidae) from eastern Amazonia and central Brazil. J Mammal 82: 109-122. 